\title{
A Generic Way of Determining Cost of Production of a Crop Using Dynamics Weights: A Case Study in Pakistan
}

\author{
Abdul Qayyum, Wasif Khurshid, Muddasar Jamil Shera* \\ Agriculture Department (Crop Reporting Service), Government of the Punjab, Lahore, Pakistan \\ Email address: \\ muddasarjamilshera@gmail.com (M. J. Shera) \\ ${ }^{*}$ Corresponding Author \\ To cite this article: \\ Abdul Qayyum, Wasif Khurshid, Muddasar Jamil Shera. A Generic Way of Determining Cost of Production of a Crop Using Dynamics \\ Weights: A Case Study in Pakistan. International Journal of Agricultural Economics. Vol. 5, No. 5, 2020, pp. 150-155. \\ doi: $10.11648 /$ j.ijae.20200505.11
}

Received: July 26, 2020; Accepted: August 13, 2020; Published: August 25, 2020

\begin{abstract}
To determine cost of production (CoP) of a crop is a persistent distress for the Government of Punjab (Pakistan) in the given conditions of rural and political dynamics. For the purpose, Crop Reporting Service (CRS), Agriculture Department Punjab has been evolving, using and analyzing sample data based on Area Frame Sampling (AFS) technique for conducting surveys to gather information regarding crop acreage, CoP, grain yield / production and other agricultural items. Timely decision on CoP of a crop by the government before the arrival of a crop is, obviously, very important for the announcement of support price for the crop and also for the evaluation of cost and benefit analysis of agriculture sector. Using AFS technique, based on two-stage sampling design, 5500 segments of 150 acre each have been selected covering almost 2600 Union Councils (UCs) of the Punjab for the study. From each randomly selected segment, two farmers were randomly selected. Through a detailed questionnaire, covering almost 75 variables on $\mathrm{CoP}$ of a crop, data are collected from the farmers of a specific crop. For this purpose wheat crop (Wheat is one of the core agricultural crops in Pakistan) has been selected as a case study for the comparison of Average (using Arithmetic Mean) CoP and Weighted Average CoP (WACoP) of wheat. In this paper, a detailed data flow and method for the determination of $\mathrm{CoP}$ of a crop is discussed. Average (using Arithmetic Mean) CoP technique was available to determine the production cost of any crop using the root level data from the farmers. But while compiling the report of COP on Punjab level, it has to be mentioned that the average cost of each head then ultimately total of all heads' averages computed to find out the average COP of the specific crop. To overcome this problem, it has been proposed a new method to determine the $\mathrm{CoP}$ of any crop by using WACoP and taking proportion of usage of a specific head as a weight of the head. Data are compiled on provincial level and proportion of each cost factor of a crop was calculated as usage of each cost factor varies from crop to crop and area to area. The proportion of each cost factor has been used as its weight for the final evaluation of $\mathrm{CoP}$ of the crop. As cost factors vary, so for, all crops during a season, each year these weights of cost factors were freshly calculated to get latest CoP of a crop. Government of Pakistan has declared Rs. 1400/40kg as support price of wheat during Rabi season 2019-20 based on this study.
\end{abstract}

Keywords: Area Frame Sampling (AFS), Cost of Production (CoP), Weighted Average Cost of Production (WACoP), CRS (Crop Reporting Service)

\section{Introduction}

Agriculture's role in the growth of economic progression has framed a vital question in development economics for several years [1]. The agriculture sector plays a very important role in Pakistan's social security and overall economic welfare. Where a large section of the population depends on agriculture for its livelihood, it is important to have detailed estimates of the costs incurred, returns realized and net income derived from farming and accounts for 24 percent of gross domestic product [2]. Detailed data on the cost of cultivation and farm incomes from different crops in different farming situations assist in formulating appropriate farm policies, and help in studying the impact of various policy measures on die well-being of cultivators. Estimating the $\mathrm{CoP}$ for agricultural products involves estimating all 
economic costs and revenues associated with the production of the commodity [3].

Crop Reporting Service (CRS), Agriculture Department, Punjab, as a unique and the largest statistical organization in Punjab, has been working on agricultural statistics using the sampling technique, Area Frame Sampling (AFS), for conducting surveys to gather information regarding crops acreage, cost of production, crops yield and other agricultural items since 1978. Cost of Production (CoP), precisely speaking, Average CoP Survey of a particular crop is one of the prime duties of CRS, Punjab. The main objective of such surveys is to provide the required empirical results for the finalization of support price of a crop, which is generally announced by Federal Government based on the recommendations from the Provincial Governments.

The comprehensive scheme for the Study of Cost of Cultivation of Crops which collects in-depth data on various aspects of farm economy across major states in Pakistan on an annual basis began from 1970-71. Ray (1915), highlight the items of cost of cultivation included in the estimate are (1) ploughing cattle, (2) agricultural implements, (3) seed, (4) manure, and (5) labor requited for ploughing, sowing reaping, etc... The method of calculation varies according to the description of crops grown, the method of cultivation, as well as according to the mode in which these items are paid in each district [4].

Gordon (1917) pointed that the cost of cultivation was calculated in the most extra ordinary detail, including not only the expenses of the labor, seed, bullock etc., but also such items as insurance against loss of cattle, fees to artificers and even the cost of propitiating the local deity at harvest time. The average gross produce was then converted to money at an average of prices for past years, and the net produce found by deducting the cost of cultivation [5]. The precision agriculture's information technologies affect crop profits, and improve crop production management through best management practices [6]. In the case of cropping pattern of marginal, small, medium and large holding size, weighted average Cost of Production (WACoP) explained the cropping intensity were marginal farmers [7].

The CoP per hectare of rapeseed mustard on the sample farms have been worked out by using weighted average method and major component of the cost was human labor (37.52 per cent), rental value of owned land (26.39 per cent). It indicated that, costs of cultivation was highest on marginal farms (Rs. 56834.60), followed by medium farms (Rs. 47184.44), large farms (Rs. 46943.53) and small farms (Rs. 49109.51). The overall average of costs of cultivation was observed (Rs. 50310.84) on sample farms [8].

Kumar (2018) highlighted that by using the weighted average, the Cost of cultivation of mustard indicates that it is an input responsive crop. Cost of cultivation was higher on medium size of farms followed by small and marginal size group of farms. It may be concluded that per hectare costs of cultivation of mustard increases with an increase in farm size [9].

Currently, CRS Punjab is calculating the CoP of crop by using the average (using Arithmetic Mean) method using the root level data from the farmers. For the collection of primary data of CoP of a particular crop, a general form has been designed covering more than 75 indicators regarding the cost features of a crop. Randomly four growers are selected from each sampled village as a subject for the said survey. Data are entered in the SPSS Builder designed form and results are compiled on District, Divisional, Provincial and Zonal (irrigated \& un-irrigated) levels accordingly. CoP almost covers all dimensions of cost from initial to maturity level at market gate level of a specific crop including the parameters, Land Preparation, Seed, Irrigation, Fertilizers (Artificial + Natural), Spray (Pesticides + Weedicides), Crop Cutting (Harvesting + Picking + Thrashing), Land Rent (Annual), Transportation, Other Costs (Administration + Tunnels + Marketing), On the average 100 growers are randomly selected in a district for the cost survey of a crop. But while compiling the report of CoP on Punjab level, we have to mention the average cost of each head then ultimately total of all head's averages is computed to find out the average CoP of the specific crop.

Now, in consolidation of CoP report on the Punjab level, we have to use a combination of Weighted Mean and Arithmetic Mean taking proportion of usage of a specific head as a weight of the head that is called WACoP.

\section{Sampling Design}

A Frame or Sampling Frame is any device used to obtain observational access to the finite population of interest [10]. Area frames are the backbone to the agricultural statistics. An area frame used to collect data for multiple variables in one survey and provided unbiased estimates with measurable precision. Once an area frame is constructed, it can be used year after year without having to update the sampling units [11].

AFS is used to collect the sample for our study. Two stage sampling techniques are being used in AFS [12]. An area frame used to collect data for multiple variables in one survey and provided unbiased estimates with measurable precision. Once an area frame is constructed, it can be used year after year without having to update the sampling units [13].

In this section two stage sampling techniques have been discussed. There is no sampling up to Union Council (UC) level i.e. representation of each UC is must in the sample. Sampling techniques have been used at village level and within a village at Land Segment level.

At Stage-I, a set of all villages of a UC is the population from which we have to select a sample of villages by using a suitable sampling technique. Each UC comprises 1 to maximum 25 villages with different areas of acreage. Some villages are significantly large and some are small. Also some villages have more area but less being used for cultivation i.e. comparatively small cropped area of a village. This fact leads to the need of implementing (Probability Proportional to size sampling i.e. villages have more 
cultivated area are more likely to be selected in the sample.

After selection of a village at Stage-I, the available land of village being used for cultivation is the population at Stage-II from which one Segment of size 150 acres is to be sampled or selected i.e. available total land of the village is broken in to all possible Segments (Primary Sampling Unit) and one Segment is selected by using the technique of Simple Random Sampling (SRS) because there is a lot of homogeneity in all agro based parameters and cropping pattern with in a village. So SRS is the best choice as a sampling technique at Stage-II.

Using AFS technique, based on two-stage sampling design, 5500 segments of 150 acre each have been selected covering almost 2600 UCs of the Punjab. From each randomly selected segment, two farmers were randomly selected. Through a detailed questionnaire, covering almost 75 variables on $\mathrm{CoP}$ of a crop, data are collected from the farmers of a specific crop. Data are compiled on provincial level and proportion of each cost factor of a crop is calculated as usage of each cost factor varies from crop to crop and area to area.

The population's layers in AFS technique are as

Division (100\% Coverage)<smiles>C1CC2CC12</smiles>

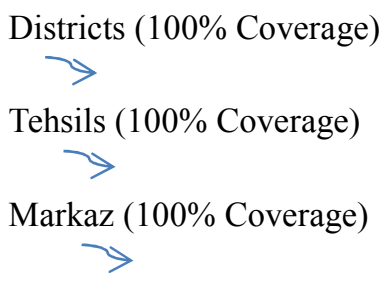

Union Council (100\% Coverage) $\rightarrow$

Village (Sampling Stage-I)

Land Segment (Sampling Stage-II)

\section{Proposed Method}

As discussed earlier Average (Using Arithmetic Mean) $\mathrm{CoP}$ is available technique to determine the production cost of any crop using the root level data from the farmers. But while compiling the report of CoP on Punjab level, we have to mention the average cost of each head then ultimately total of all head's averages is computed to find out the average CoP of the specific crop.

In this section, proposed method to determine the CoP of any crop by using WACoP, has been discussed. In consolidation of CoP report on the Punjab level, we have to use a combination of Weighted Mean and Arithmetic Mean taking proportion of usage of a specific head as a weight of the head.

Total Average COP $=\frac{\text { Total of all heads of Cost }}{\text { Total number of farmers in the sample }}$
Total Average CoP $=\frac{\sum_{i=1}^{n} n_{i} \bar{X}_{i}}{\sum_{i=1}^{n} n_{i}}$ (Pool mean)

Expand form of (1) is given below

Total Average CoP $=\frac{n_{1} \bar{X}_{1}+n_{2} \bar{X}_{2}+n_{3} \bar{X}_{3}+\sum_{i=4}^{n} n_{i} \bar{X}_{i}}{\sum_{i=1}^{n} n_{i}}$

or

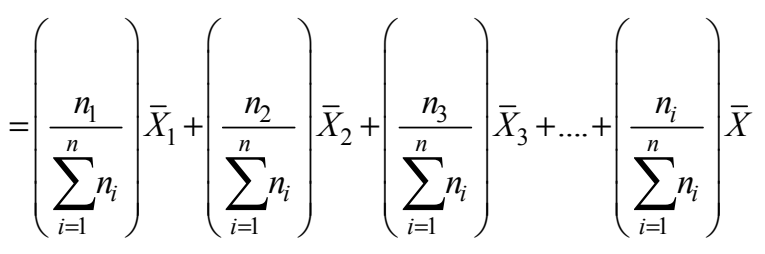

Total Average $C o P=P_{1} \bar{X}_{1}+P_{2} \bar{X}_{2}+P_{3} \bar{X}_{3}+\ldots .+P_{i} \bar{X}_{i}$

For cost of heads, which are applied by $100 \%$ farmers like seed cost, water cost and harvesting cost etc.

$$
\begin{gathered}
P_{i}=1 \\
\text { Total Average } \mathrm{CoP}=\sum_{i=1}^{K} P_{i} \bar{X}_{i}+\sum_{J=1}^{m} \bar{X}_{J}
\end{gathered}
$$

Where,

$\bar{X}_{i}:$ Mean of $i^{\text {th }}$ head of CoP

$P_{i}$ : Proportion of farmers using $i^{\text {th }}$ head of Cost of Production

$\mathrm{m}$ : Total number of cost heads used by $100 \%$ farmers

$\mathrm{k}$ : Total number of cost heads not used by $100 \%$ farmers

The above method can be illustrated by the following hypothetical examples shown in the Table 1.

Table 1. Hypothetical Case.

\begin{tabular}{lllll}
\hline \multirow{2}{*}{ Farmers } & \multicolumn{2}{l}{ Head of Cost (/ Acre) } & Total Cost \\
\cline { 2 - 5 } & A & B & C & (A+B+C) \\
\hline 1 & 47 & 257 & 55 & 359 \\
2 & 68 & 749 & 66 & 883 \\
3 & 87 & 872 & 79 & 1038 \\
4 & 12 & 635 & 33 & 680 \\
5 & 14 & 269 & 30 & 313 \\
6 & 54 & 246 & 72 & 372 \\
7 & 78 & 365 & 67 & 510 \\
8 & 35 & 254 & 57 & 346 \\
9 & 65 & 312 & 67 & 444 \\
10 & 47 & 743 & & 790 \\
11 & 98 & 610 & & 708 \\
12 & 14 & 406 & & 420 \\
13 & 54 & 757 & & 811 \\
14 & 20 & 399 & & 419 \\
\hline
\end{tabular}




\begin{tabular}{lllll}
\hline \multirow{2}{*}{ Farmers } & \multicolumn{2}{l}{ Head of Cost (/ Acre) } & Total Cost \\
\cline { 2 - 4 } & $\mathbf{A}$ & $\mathbf{B}$ & $\mathbf{C}$ & $\mathbf{( A + B + C )}$ \\
\hline 15 & 30 & & 30 \\
16 & 56 & & 56 \\
17 & 89 & & 89 \\
18 & 41 & & 41 \\
19 & 83 & & 83 \\
20 & 70 & & 70 \\
21 & 64 & & 64 \\
22 & 52 & & 52 \\
23 & 39 & & 39 \\
24 & 49 & & 49 \\
25 & 79 & & & 79 \\
Sum & 1345 & 6874 & 526 & 8745 \\
Average & 53.8 & 491 & 58.4 & 350 \\
\% Share & $(100 \%)$ & $(56 \%)$ & $(36 \%)$ & \\
\hline
\end{tabular}

There are 25 farmers using three Heads of Cost (/acre); A, $\mathrm{B}, \& \mathrm{C}$ for the production of a specific crop. But all Heads of Cost have not been used by all the farmers i.e. different farmers have different combinations of costs as Head-A has been used by $100 \%$ farmers, Head-B by $56 \%$ and Head-C by $36 \%$ as mentioned in the Table 1 .

Total CoP (/acre) of the crop by all the 25 farmers is 8744 and, obviously, Average CoP (/acre) is $350(8744 \div 25)$ as shown in the last column of Table 1. While consolidating $\mathrm{CoP}$ on Punjab level, we have to mention percentage usage of each cost of Head and using these percentages, we have to find out Average CoP. Using the formula,

Total Average CoP $=\frac{\text { Total of all heads of Cost }}{\text { Total number of farmers in the sample }}$

$$
\text { Total Average CoP }=\frac{n_{A} \bar{X}_{A}+n_{B} \bar{X}_{B}+n_{C} \bar{X}_{C}}{25}
$$

Total of all heads of cost $=\frac{25(53.8)+14(491)+9(58.4)}{25}$

or

Total of all heads of cost $=\frac{25(53.8)+25(0.56) 491+25(0.36) 58.4}{25}$

$$
\begin{aligned}
& =53.8+275+21.2 \\
& =350(\text { Grand Mean as in Table } 1)
\end{aligned}
$$

\section{Results}

Wheat is one of the core agricultural crops in Pakistan, with 80 percent of farmers growing it on an area of around sixteen million acre during the winter season. This crop alone contributed about 10 percent of value added in agriculture and 2.1 percent of the country's gross domestic product (GDP) in 2015 [14]. In addition, wheat is essential for Pakistan's food security [15].

Results of CoP are used in multiple dimensions like for fixation of area target of a crop or volume of import / export of a crop and per acre cost of production of a crop plays a pivotal role to assess the crop's viability.

For this reason we select the wheat crop for the comparison of Average (Using Simple Average) CoP and WACoP of wheat. On the basis of above method, a consolidated report of Simple and WACoP of wheat is given in the Table 2. In the column of "Percentage of Usage (\%)", blank entries show $100 \%$ usage of the specific head, otherwise $\%$ is shown.

Table 2. Simple and Weighted Average Cost of Production Comparison.

\begin{tabular}{llllll}
\hline No. & Operation/ Inputs & $\begin{array}{l}\text { Avg. No. of Operation/Unit } \\
\text { (/Acre) }\end{array}$ & $\begin{array}{l}\text { Percentage of } \\
\text { Usage (\%) }\end{array}$ & $\begin{array}{l}\text { Avg. Cost per Operation/ Unit } \\
\text { (Rs./acre) }\end{array}$ & $\begin{array}{l}\text { Total Weighted } \\
\text { Cost (Rs. /acre) }\end{array}$ \\
\hline \multirow{2}{*}{1} & Deep Ploughing & 1.26 & $22 \%$ & 1292 & 358 \\
& Ploughing & 3.52 & $100 \%$ & 707 & 2489 \\
& Planking & 1.75 & $100 \%$ & 429 & 751 \\
& Leveling & 1 & $32 \%$ & 1291 & 413 \\
& Cost of Land Prep & & & 3719 & 4011 \\
& Seed Quantity (kg) & 52 & $100 \%$ & 40 & 2080 \\
& Seed Drilling & 1 & $30 \%$ & 777 & 233 \\
2 & Seed Broadcasting & 1 & $70 \%$ & 211 & 148 \\
& Seed Treatment & 1 & $1 \%$ & 284 & 12 \\
& Bridging & 1 & $4 \%$ & 300 & 2476 \\
& Cost of Seed \& Sowing & & & 1612 & 2858 \\
& Water No & 3.85 & $80 \%$ & 928 & 137 \\
& Water Labour & 1 & $80 \%$ & 171 & 28 \\
\hline
\end{tabular}




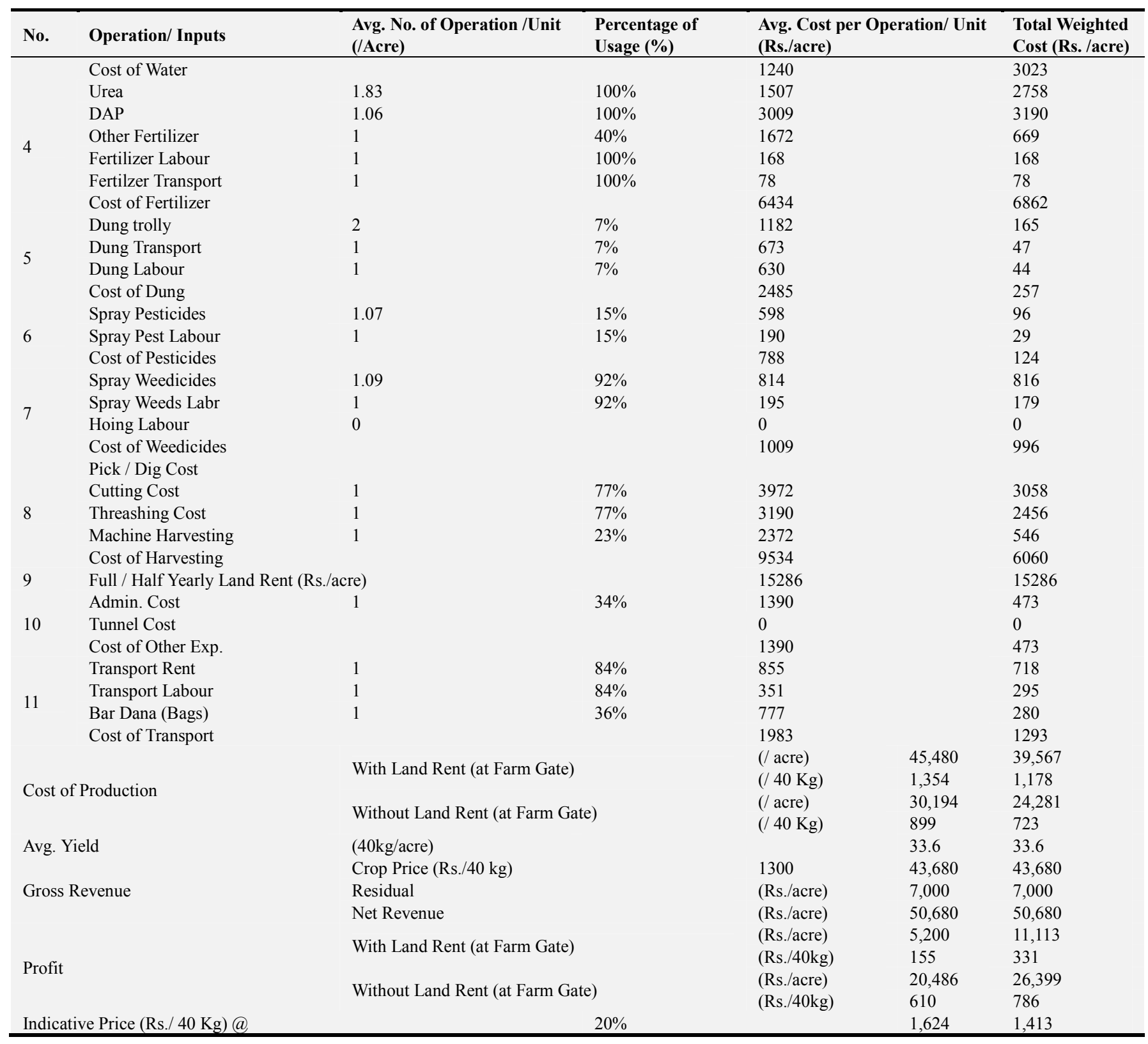

There are 11 heads of cost and each head has a further break-up of its sub-heads as shown in the Table 2. For each head simple and weighted cost of production is calculated and Total Weighted Average CoP is calculated i.e. Rs. 39,567/acre $\&$ Rs. $1,178 / 40 \mathrm{~kg}$. On the other hand, simple average cost of production is calculated i.e. Rs. $45,480 /$ acre \& Rs. $1353 / 40 \mathrm{~kg}$. Government of Pakistan declare wheat support price to the farmers before the harvesting of crop which is based on indicative price computed by Crop Reporting Service. According to above Table 2, indicative price of wheat computed Rs. 1413 based on WACoP. And Government of Pakistan declared Rs. 1400/40kg as support price of wheat during Rabi season 2019-20 based on this study.

\section{Conclusion}

The agriculture sector plays a very important role in
Pakistan's social security and overall economic welfare. Determination of cost of production of a crop has been great concerned by the Government of Punjab (Pakistan) all the times. Results of CoP are used in multiple dimensions like for fixation of area target of a crop or volume of import / export of a crop and per acre cost of production of a crop plays a pivotal role to assess the crop's viability. Mostly, CoP reports are generated bearing individual minimum, maximum and mean values of each head of cost i.e. independently for each variable involved in the $\mathrm{CoP}$ analysis. For the purpose, CRS Agriculture Department Punjab has been evolving, using and analyzing the sampled data based on AFS technique for conducting surveys to gather information regarding crop acreage, CoP, grain yield / production and other agricultural items. Timely decision on $\mathrm{CoP}$ of a crop by the government before the arrival of a crop is, obviously, very important for the announcement of support price of the 
crop and also for the evaluation of cost and benefit analysis of agriculture sector. Using AFS technique, based on twostage sampling design, 5500 segments of 150 acre each have been selected covering all 2600 UCs of the Punjab for the study. From each randomly selected segment, four farmers were randomly selected. Through a detailed questionnaire, covering almost 75 variables on $\mathrm{CoP}$ of a crop, data are collected from the farmers of a specific crop. For this purpose wheat crop (Wheat is one of the core agricultural crops in Pakistan) has been selected as a case study for the comparison of Average (using Arithmetic Mean) $\mathrm{CoP}$ and WACoP of wheat. In this paper, a detail data flow and method for the determination of CoP of a crop have been discussed. Average (using Arithmetic Mean) CoP technique was available to determine the production cost of any crop using the root level data from the farmers. But while compiling the report of COP on Punjab level, it has to be mentioned the average cost of each head then ultimately total of all heads' averages computed to find out the average COP of the specific crop. To overcome this problem, it has been proposed a new method to determine the COP of any crop by using WACoP and used a combination of Weighted Mean and Arithmetic Mean taking proportion of usage of a specific head as a weight of the head. Data are compiled on provincial level and proportion of each cost factor of a crop was calculated as usage of each cost factor varies from crop to crop and area to area. The proportion of each cost factor has been used as its weight for the final evaluation of CoP of the crop. As cost factors vary from crop to crop and area to area of the Punjab, so for, all crops during a season, each year these weights of cost factors were freshly calculated to get latest $\mathrm{CoP}$ of a crop. Government of Pakistan declare wheat support price to the farmers before the harvesting of crop which is based on indicative price computed by Crop Reporting Service. And Government of Pakistan declared Rs. $1400 / 40 \mathrm{~kg}$ as support price of wheat during Rabi season 2019-20 based on this study.

\section{Acknowledgements}

The authors are grateful to the whole field staff of CRS for the provision of the data used in this study.

\section{References}

[1] Johnston, F. B., Mellor, John W. (1961) The role of agriculture in economic development. The American Economic Review. Vol. 51 No. 1, pp. 566-593.
[2] Agriculture, Pakistan Bureau of Statistics. "Agriculture Pakistan Bureau of Statistics". Retrieved 1 April 2019.

[3] FAO. Handbook on Agriculture cost of production statistics, Guidelines for Data Collection, Compilation and Dissemination, 2016.

[4] Ray, S. C. (1915) Land Revenue Administration in India, University of Calcutta, Calcutta.

[5] Gordon, R. G. (1917) The Bombay Survey and Settlement Manual, volumes I and II, Government Central Press, Bombay.

[6] Schimmelpfennig, D. (2018) Crop Production Costs, Profits, And Ecosystem Stewardship With Precision Agriculture. Journal of Agricultural and Applied Economics, Vol 50 No. 1, pp. 81-103.

[7] Kumar, P. (2019) Economic study of mustard (Brassica oleracea) growers in Meerut district of western Uttar Pradesh. Journal of Pharmacognosy and Phytochemistry, Vol 8 No. 1, pp. 1443-1447.

[8] Kumar, P., Singh, K., Singh, P. S., (2017) Cost Of Cultivation On Mustard (Brassica Olerasia) In Meerut District Ofwestern Uttar Pradesh, India. Plant Archives Vol. 17 No. 2, pp. 14921494.

[9] Sahu, K. P., Kant, K., Choudhari, P. H., Singh, G. P. (2018) Cost of cultivation in mustered crop in Fatehpur district of Uttar Pradesh. International Journal of Current Microbiology and Applied Sciences, Vol. 7 No. 8, pp. 224-229.

[10] Sardnal EC, Swensson B, Wretmen J. Model assisted survey sampling, Springer; 2003.

[11] Qayyum, A., Shera, M. J., (2019) Method of Area Frame Sampling Using Probability Proportional to Size Sampling Technique for Crops' Surveys: A Case Study in Pakistan. Journal of Experimental Agriculture International, Vol. 41 No. 2, pp. 1-10.

[12] Cotter, J., Davies, C., Nealon, J., \& Roberts, R. (2010) Area frame design for agricultural surveys. Agricultural survey methods, pp. 169-192.

[13] Davies C, Cotter J, Nealon J, Roberts R. (2010) Area frame design for agricultural surveys. Agricultural Survey Methods, pp. 169-192.

[14] Iqtidar, H., Ayyaz, K. M., Ahmad, K. E., 2006. Bread wheat varieties as influenced by different nitrogen levels. Journal of Zhejiang University, Vol. 7, pp. 70-78.

[15] Khan, N. Z., Ahmad, M., Rasheed, A., (2003) Wheat production in Pakistan: Saga of policy disincentives. Pakistan Development Review, Vol. 42 No. 1, pp. 1-27. 